\title{
Compósitos Bioativos Obtidos a Partir da Inserção de Vidro Bioativo em Matriz de Poli(Metacrilato de Metila)
}

\author{
Paulo E. Silva J unior, Rodrigo L. Oréfice \\ LEPCom, Departamento de Engenharia Metalúrgica e de Materiais, UFMG
}

\begin{abstract}
Resumo: Várias biocerâmicas são capazes de se ligarem a tecidos vivos (bioatividade), no entanto apresentam propriedades mecânicas muito diferentes daquelas exibidas por tecidos naturais. Tal fato acaba por restringir o uso desses materiais em um mais extenso número de aplicações biomédicas. Compósitos de matriz polimérica reforçada com uma fase bioativa podem combinar o comportamento bioativo característico de algumas biocerâmicas com propriedades mecânicas próximas à de tecidos humanos. O presente trabalho tem como objetivo sintetizar e caracterizar compósitos de matriz polimérica reforçada por partículas de vidro bioativo. Os compósitos foram produzidos a partir da polimerização em massa de metacrilato de metila na presença de partículas de vidro bioativo (vidro de silicato de cálcio, fósforo e sódio). Partículas de vidro foram adicionadas ao monômero em diversas concentrações para permitir a variação das propriedades mecânicas e da bioatividade desses compósitos. A bioatividade dos materiais produzidos foi avaliada através de testes in vitro realizados a $37^{\circ} \mathrm{C}$ em uma solução simuladora do fluido humano por períodos de tempo de 0 hora a 30 dias. Em seguida, os compósitos submetidos aos testes in vitro foram caracterizados por espectroscopia de infravermelho. O procedimento de síntese mostrou-se eficaz na produção de compósitos com diferentes frações volumétricas de partículas distribuídas homogeneamente pelo material. Os resultados dos testes in vitro revelaram a deposição de uma camada de hidroxiapatita carbonatada (HCA) na superfície dos materiais, comprovando a bioatividade dos compósitos. Foi ainda observado que a cinética de deposição da camada de HCA pode ser controlada pela fração volumétrica da fase bioativa.
\end{abstract}

Palavras-chave: Compósitos, biomateriais, bioatividade, poli(metacrilato de metila), vidros bioativos.

\section{Bioactive Composites Obtained from Bioactive Glass Particles into Poly(Methyl Methacrylate)}

Abstract: Some bioceramics have the ability to bind to tissues but they show mechanical properties very different from the ones of natural tissues. This fact restricts the use of these materials in a wider range of applications. The goal of this research is to synthesize and characterize polymer matrices reinforced with bioactive glass particles that potentially can combine ability to bond to tissues (bioactivity), with mechanical properties comparable to damage tissues. The composites were produced by bulk polymerization of methyl methacrylate in the presence of bioactive glass particles and an initiator at $60^{\circ} \mathrm{C}$. Bioactive glass particles were added to the monomer in several concentrations to modify the mechanical properties and bioactivity of the composites. The bioactivity of the materials was evaluated by in vitro tests performed at $37^{\circ} \mathrm{C}$ in a simulated body fluid for periods of time ranging from 1 hour to 30 days. The composites submitted to in vitro tests were characterized by infrared spectroscopy. The results revealed the deposition of a hidroxycarbonate-apatite layer on the surface of the composites, confirming their bioactivity. It was also observed that the fraction of the bioactive phase in the composites can be used to control the overall kinetics of the bioactivity process.

Keywords: Composites, bioactive glasses, biomaterials, poly(methylmethacrylate), bioactivity.

Autor para correspondência: Rodrigo L. Oréfice, LEPCom, Departamento de Engenharia Metalúrgica e de Materiais, UFMG, Rua Espírito Santo, 35/316, CEP:30160-030, Belo Horizonte, MG. E-mail: rorefice@demet.ufmg.br 


\section{Introdução}

A introdução de biomateriais no corpo humano é uma das formas mais usuais de se restaurar ou substituir partes ou a totalidade de tecidos não-produtivos, fruto de traumas ou tumores. Uma série de fatores tem incentivado o desenvolvimento de novos biomateriais com comportamento superior e para novas aplicações. Dentre esses fatores, destaca-se: fraco desempenho dos materiais utilizados atualmente que são projetados para executarem suas funções por um período máximo de 10 anos (com o aumento do tempo de vida médio da população, torna-se necessário o desenvolvimento de biomateriais com propriedades superiores e capazes de cumprir suas atividades por tempos mais prolongados $\left.{ }^{[1,2]}\right)$; necessidade de se reduzir o número de cirurgias de revisão destinadas a substituir implantes danificados ${ }^{[1]}$; (no Brasil) necessidade de se atender a uma crescente demanda interna do produto e de se reduzir o custo dos materiais envolvidos; falta de doadores para transplantes.

Mais de 50 diferentes dispositivos constituídos de mais de 40 diferentes materiais são usados atualmente como forma de reparo, substituição ou auxílio à partes do corpo. A escolha de um material para ser usado como biomaterial passa necessariamente pela análise de um conjunto de requisitos que devem ser encontrados. Assim sendo, um material apto a ingressar na classe de biomateriais deve exibir propriedades coerentes com a função específica do implante (mecânica, no caso do sistema ósseo, e óptica, no caso de lentes intraoculares). Além disso, o efeito do ambiente orgânico no material (corrosão, degradação) e o efeito do material no organismo são fenômenos que devem ser estudados com extremo cuidado, pois a eles está associado a chamada "biocompatibilidade". A interação dos tecidos vivos com o biomaterial, associada com o tipo de resposta do organismo à presença do material, é o ponto mais desafiador no desenvolvimento de biomateriais. Os tipos de interação entre tecido e implante são fundamentalmente dependentes do tipo de material e podem ser reunidos nos seguintes grupos ${ }^{[1]}$ : tóxica, não-tóxica (muitas vezes chamada de bioinerte), bioativa e biodegradável. Mais recentemente, o desenvolvimento de materiais considerados bioativos e biodegradáveis vem sendo enfatizado já que, além de substituir tecidos traumatizados, estes materiais também podem propiciar a recuperação do tecido danificado através da atuação em metabolismos intra e extracelulares responsáveis pela reprodução celular e propagação dos tecidos em crescimento.

A bioatividade de materiais foi inicialmente descrita para as chamadas biocerâmicas (hidroxiapatita, vidros bioativos, etc. $)^{[3]}$. A bioatividade foi associada à capacidade de materiais se ligarem, ou aderirem a tecidos vivos. Deve-se salientar que quando da introdução de materiais ditos inertes no corpo, como o silicone, o poli(metacrilato de metila), ouro, platina, e outros, há a formação de uma fina camada fibrosa ao redor do implante que impede uma adesão entre o implante e o tecido receptor. No entanto, a obtenção desta adesão mostra-se de fundamental importância para implantes introduzidos com o objetivo de substituir partes do corpo que exerçam funções estruturais. Dessa maneira, percebe-se a importância do conceito de bioatividade. Tal conceito deve ser entendido de forma mais geral como a capacidade dos materiais de interagir com os tecidos vivos de tal modo a estimular processos físico-químicos inerentes a sistemas biológicos capazes de permitir a integração do biomaterial no ambiente receptor.

Quando um material bioativo é implantado no corpo humano, uma série de reações bioquímicas e biofísicas ocorre na interface implante-tecido. Estas reações resultam em uma forte interação interfacial associada à formação de uma camada de hidroxiapatita carbonatada (HCA) na superfície do implante ${ }^{[3]}$.

A bioatividade dos materiais pode ser avaliada tanto in vivo quanto in vitro. Os ensaios in vitro são capazes de evidenciar algumas das reações características da bioatividade de materiais. Tais testes ain-

Tabela 1. Reações na interface de um compósito biotivo para a formação da camada de HCA

\begin{tabular}{|c|c|}
\hline Estágio & Processos Físicos Químicos \\
\hline 1 & $\begin{array}{l}\text { Troca iônica de } \mathrm{Na}^{+} \text {pertencentes ao material com } \\
\mathrm{H}^{+} \mathrm{e} \mathrm{H}_{3} \mathrm{O}^{+} \text {da solução. } \mathrm{Si}-\mathrm{O}-\mathrm{Na}^{+}+\mathrm{H}^{+}+\mathrm{OH}^{-} \rightarrow \mathrm{SiOH}^{+} \\
+\mathrm{Na}^{+}{ }_{\text {(solução) }}+\mathrm{OH}^{-}\end{array}$ \\
\hline 2 & $\begin{array}{l}\text { Perda de sílica solúvel do material na forma de } \\
\mathrm{Si}(\mathrm{OH})_{4} \text { para a solução e formação da camada de } \\
\mathrm{Si}-\mathrm{OH} \text {. }\end{array}$ \\
\hline 3 & $\begin{array}{l}\text { Policondensação da camada rica em sílica na } \\
\text { superfície do material. } \mathrm{Si}-\mathrm{OH}+\mathrm{Si}-\mathrm{OH} \rightarrow \mathrm{Si}-\mathrm{O}-\mathrm{Si}\end{array}$ \\
\hline 4 & $\begin{array}{l}\text { Migração dos grupos } \mathrm{Ca}^{+2} \text { e } \mathrm{PO}_{4}^{-3} \text { para a superfície } \\
\text { através da camada rica em sílica e posterior } \\
\text { crescimento da camada amorfa rica em } \mathrm{CaO}-\mathrm{P}_{2} \mathrm{O}_{5} \\
\text { pela incorporação do } \mathrm{Ca}^{+2} \text { e } \mathrm{PO}_{4}^{-3} \text { da solução. }\end{array}$ \\
\hline 5 & $\begin{array}{l}\text { Cristalização da camada de Hidroxiapatita } \\
\text { Carbonatada (HCA) }\end{array}$ \\
\hline
\end{tabular}


da são importantes para estudar e estabelecer os estágios do mecanismo de ligação entre os tecidos vivos e os materiais bioativos, os quais são descritos na Tabela $1^{[2]}$.

Biocerâmicas apresentam alto grau de bioatividade. Por outro lado, apresentam propriedades mecânicas, em geral, não adequadas à necessidade de produção de implantes para fins estruturais ${ }^{[4]}$. Cerâmicas são caracterizadas por apresentar baixa tenacidade à fratura (por exemplo, vidro bioativos apresentam valores de $\mathrm{k}_{\mathrm{IC}}$ inferiores a $1 \mathrm{MPa} \cdot \mathrm{m}^{1 / 2}$ ) e altos módulos de elasticidade (o módulo de elasticidade de vidros bioativos é igual a $80 \mathrm{GPa}$ ) quando comparadas com o osso cortical humano (módulo de elasticidade varia de 7-20 GPa ${ }^{[3]}$ que comprometem o uso e processamento desses materiais para aplicações biomédicas. Como solução para a necessidade de produção de materiais bioativos com propriedades mecânicas mais comparáveis à de tecidos como o osso cortical, pode ser citada a produção de compósitos envolvendo a fase bioativa (cerâmica) e um segundo componente.

O objetivo deste trabalho está relacionado com a produção de materiais bioativos que apresentem o comportamento bioativo típico de cerâmicas bioativas (capacidade de ligação com tecidos), além de possuir propriedades mecânicas comparáveis à de tecidos como o osso. Como forma de se compatibilizar tais fatores (bioatividade e propriedades mecânicas), propõe-se aqui a preparação de compósitos de matriz polimérica reforçados por fases cerâmicas bioativas. Nesse caso, tais fases cerâmicas seriam responsáveis não apenas por reforçar a matriz polimérica, como usualmente ocorre quando da introdução de fibras de vidro em polímeros, mas também por prover as características bioativas desejadas. Este trabalho faz parte de uma linha de pesquisa voltada para o desenvolvimento de Biomateriais capazes de elucidarem respostas inflamatórias e imunológicas controladas quando em contato com tecidos vivos.

\section{Experimental}

Na síntese dos compósitos foram utilizados os seguintes reagentes: metacrilato de metila (Aldrich Chemical Company, Inc), poli(metacrilato de metila) (Metacril), peróxido de benzoíla (VETEC - Química Fina Ltda.) (iniciador) e partículas de vidro bioativo. Utilizou-se partículas de vidro bioativo com tama- nho médio de $75 \mu \mathrm{m}$ e composição molar de 46,1\% de $\mathrm{SiO}_{2}, 24,4 \%$ de $\mathrm{Na}_{2} \mathrm{O}, 26,9 \%$ de $\mathrm{CaO}$ e $2,6 \%$ de $\mathrm{P}_{2} \mathrm{O}_{5}$. O vidro bioativo foi obtido via fusão de pós, a seguir este material sofreu resfriamento rápido, moagem e classificação granulométrica por peneiras.

Neste trabalho foram sintetizados compósitos com $0 \%, 10 \%, 20 \%$ e $50 \%$ em massa de partículas de vidro bioativo.

\section{Procedimentos}

\section{Síntese}

O metacrilato de metila foi purificado em uma coluna de cromatografia preenchida com alumina. A introdução do poli(metacrilato de metila) no monômero foi realizada visando aumentar a viscosidade do mesmo (25\% em massa), de modo que as partículas ficassem em suspensão.

À essa mistura, acrescentou-se o iniciador peróxido de benzoíla (1\% em massa de monômero) e as partículas de vidro. A mistura foi agitada até a completa homogeneização e, então, vazada num molde produzido por duas placas de vidro separadas por uma mangueira elástica. Por fim, levou-se o molde bem vedado até estufa a cerca de $60^{\circ} \mathrm{C}$ por doze horas. Visando eliminar resíduos de monômeros não polimerizados, submeteu-se as amostras a um tratamento térmico final a $130^{\circ} \mathrm{C}$ por cerca de vinte minutos em estufa.

A superfície de fratura de compósitos foi investigada por Microscopia Eletrônica de Varredura. Amostras do polímero contendo partículas de vidro foram fraturadas, após resfriamento a temperaturas criogênicas. A superfície de fratura foi recoberta com liga Au-Pd e em seguida observada em microscópio eletrônico de varredura (Jeol).

\section{Testes in vitro}

A fim de revelar as partículas introduzidas, as superfícies das amostras foram lixadas com lixas de carbeto de silício (\#320, \#600). As amostras foram então cortadas em dimensões médias de $1 \times 1 \times 0,3 \mathrm{~cm}$.

A bioatividade dos compósitos produzidos foi avaliada seguindo um procedimento usualmente utilizado para a caracterização in vitro de vidros bioativos. Estudos prévios in vivo ${ }^{[5]}$ mostraram que a condição essencial para um material se ligar com o tecido é a formação de uma camada de hidroxiapatita carbonatada (HCA) em ambiente orgânico. O teste 
in vitro se constituiu em introduzir compósitos preparados com diferentes concentrações de vidro bioativo $(0 \%, 10 \%, 20 \%, 50 \%$ em massa) em uma solução simuladora do fluido humano (SBF). A SBF apresenta uma composição iônica similar à do sangue $^{[6]}$. Os testes foram realizados a $37^{\circ} \mathrm{C}$ por diferentes períodos de tempo variando de 1 hora a 30 dias. Depois de realizados os testes in vitro, os compósitos foram caracterizados através de espectroscopia por reflexão difusa no infravermelho médio com transformada de Fourier (FTIR).

$\mathrm{O}$ volume de solução $\mathrm{SBF}$ empregado no ensaio de bioatividade depende da área superficial da amostra. Estudos anteriores ${ }^{[5]}$ demonstraram que uma relação entre a área superficial da amostra e o volume da solução $\mathrm{SBF}(\mathrm{SA} / \mathrm{V})$ igual a $0,1 \mathrm{~cm}^{-1}$ representa satisfatoriamente ambientes de implantação.

A caracterização dos compósitos obtidos foi feita através de análise térmica, espectroscopia por reflexão difusa no infravermelho médio com transformada de Fourier e absorção atômica. As análises térmicas, através das técnicas de Termogravimetria (Shimadzu, TGA-50H) e Calorimetria Exploratória Diferencial (Shimadzu, DSC-50), avaliaram respectivamente a porcentagem de material particulado inserido na matriz polimérica e a temperatura de transição vítrea das amostras. Na técnica de Termogravimetria, amostras pesando aproximadamente $10 \mathrm{mg}$ foram colocadas no equipamento e submetidas a uma temperatura de $1000^{\circ} \mathrm{C}$, sob uma taxa de aquecimento de $10^{\circ} \mathrm{C} / \mathrm{min}$ e atmosfera de nitrogênio. Para a análise de calorimetria exploratória, amostras pesando aproximadamente $10 \mathrm{mg}$ foram colocadas no equipamento e aquecidas até $250^{\circ} \mathrm{C}$ a uma taxa de aquecimento de $10^{\circ} \mathrm{C} / \mathrm{min}$. A técnica de espectroscopia por reflexão difusa no infravermelho médio com transformada de Fourier (Perkim-Elmer, Paragon 1000) foi escolhida devido a sua capacidade de prover informações de superfícies rugosas, particulados e outros. A técnica de absorção atômica avaliou quantitativamente alterações da concentração do íon cálcio na solução SBF em função do tempo de ensaio nos testes in vitro.

\section{Resultados}

O termograma mostrado na Figura 1 permite observar a presença de resíduos nas curvas TGA e a correlação da quantidade de resíduo com o conteúdo de partículas inseridas no compósito. Observa-se pelo

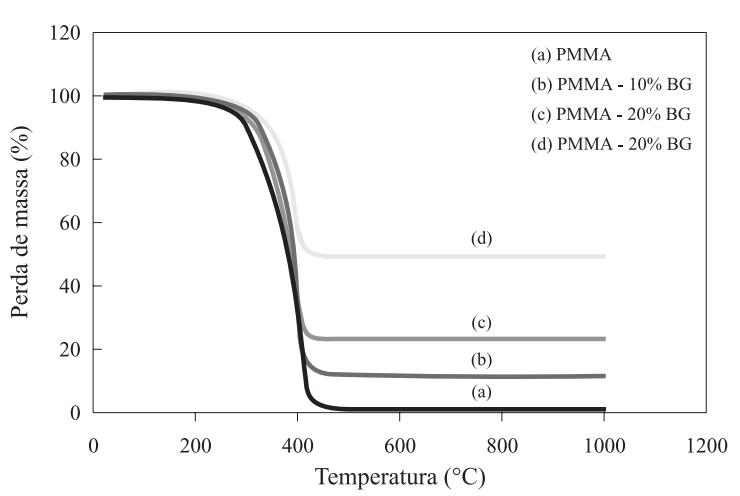

Figura 1. Análise termogravimétrica de compósitos PMMA-vidro bioativo.

resultado que a massa após a queima do polímero em temperaturas acima de $600^{\circ} \mathrm{C}$ confirma as frações de partículas de vidro bioativo inseridas no compósito $(10 \%, 20 \%$ e $50 \%)$.

Termogramas DSC de PMMA puro e do compósito PMMA-partículas de vidro bioativo com $20 \%$ em massa de particulado mostraram que a temperatura de transição vítrea do PMMA (em torno de $105^{\circ} \mathrm{C}$ ) é deslocada para temperatura $5^{\circ} \mathrm{C}$ maior com a adição do material particulado. Sabe-se que o erro do equipamento é de $\pm 3^{\circ} \mathrm{C}$, demostrando que o aumento de Tg é significativo. Este resultado indica que as partículas introduzidas no compósito estão modificando o comportamento viscoelástico da matriz polimérica através da introdução de empecilhos ao deslocamento livre das cadeias. Assim, tem-se uma forte indicação de que interações interfaciais estão sendo responsáveis por um aumento da viscosidade relativa do polímero em regiões próximas à interface. A presença de interações interfaciais permite prever que níveis médios a elevados de resistência mecânica interfacial existam no compósito preparado.

A Figura 2 mostra uma micrografia obtida por Microscopia Eletrônica de Varredura da superfície de fratura do compósito com $20 \%$ em massa de partículas de vidro bioativo. A análise desta superfície permite identificar a presença de partículas de vidro. Tal presença de partículas na superfície sugere, através de uma análise da morfologia da superfície de fratura, que a resistência mecânica interfacial entre partículas e matriz pode ser classificada como intermediária em magnitude. Resistências interfaciais baixas são geralmente identificadas em superfícies de fratura pela ausência de partículas, o que denota a propagação das trincas pela região interfacial. Já re- 


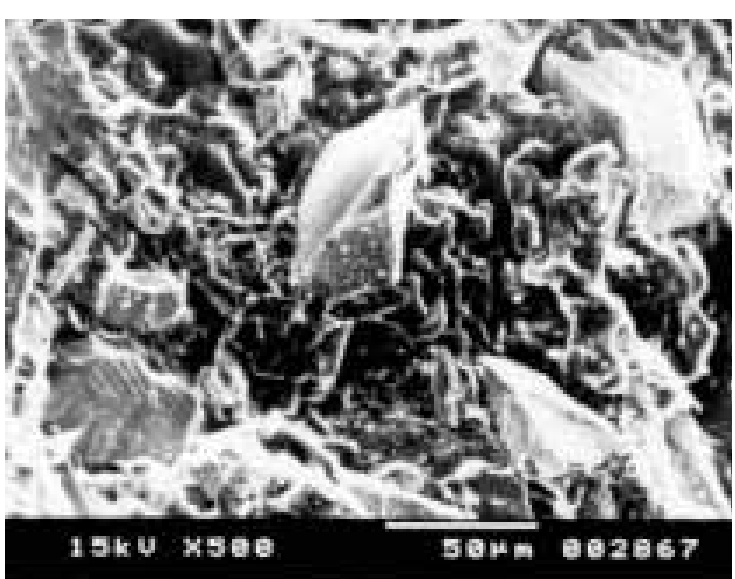

Figura 2. Micrografia (MEV) da superfície de fratura de compósito com PMMA-20\% em massa de partículas de vidro bioativo.

sistências interfaciais elevadas são comuns para superfícies de fratura caracterizadas pela presença de filmes poliméricos sobre partículas. No caso da superfície de fratura em análise, a presença de partículas com superfícies reveladas caracteriza a existência de níveis de resistência intermediários entre os casos extremos citados (resistências interfaciais altas e baixas).

A Figura 3-a exibe o espectro de FTIR do poli(metacrilato metila) puro, no qual se observam as bandas de absorção de número de onda característico dos grupos carbonila $\left(1706 \mathrm{~cm}^{-1}\right)$, metila $\left(2800 \mathrm{~cm}^{-1}\right)$, $\mathrm{C}-\mathrm{O}\left(1100 \mathrm{~cm}^{-1}\right)$ do polímero, entre outras. Nas Figuras 3-b, 3-c e 3-d, observa-se os espectros relativos à superfície dos compósitos de $10 \%, 20 \%$ e $50 \%$ em massa de partículas respectivamente, antes dos testes in vitro. A diferença entre os espectros de compósitos e de PMMA puro se revela principalmente nas regiões

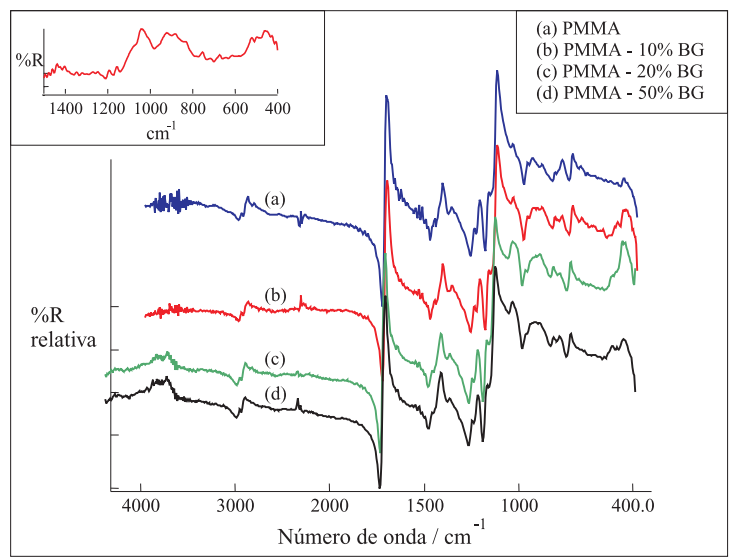

Figura 3. Espectros de FTIR do PMMA e dos compósitos contendo $10 \%, 20 \%$ e $50 \%$ em massa de partículas de vidro bioativo em uma matriz de PMMA antes do teste in vitro

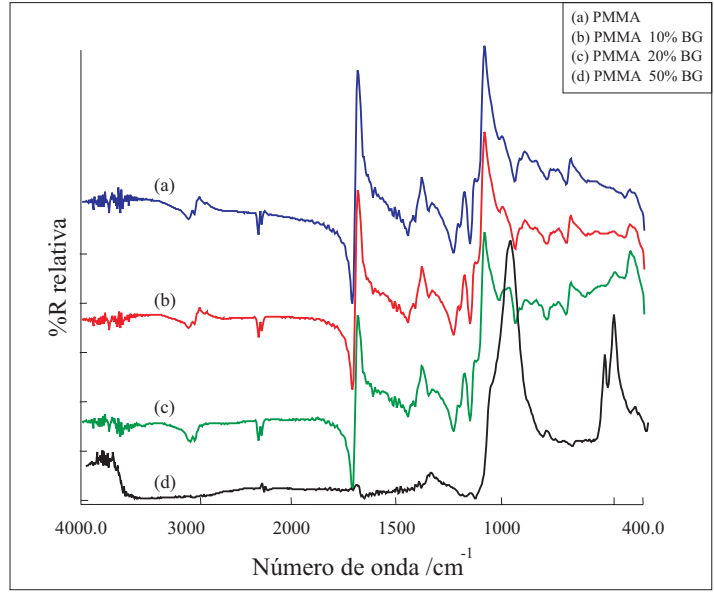

Figura 4. Espectros FTIR para compósitos após 20 horas in vitro

de número de onda característico das ligações $\mathrm{Si}-\mathrm{O}-\mathrm{Si}$ (estiramento, $1090 \mathrm{~cm}^{-1}$ ), $\mathrm{SiOH}$ (estiramento, $950 \mathrm{~cm}^{-1}$ ) e $\mathrm{SiO}$ (flexão, $400 \mathrm{~cm}^{-1}$ ), como mostrado no espectro situado na parte superior esquerda da Figura 3, o qual foi obtido pela subtração dos espectros (a) e (d) da mesma figura.

Os resultados dos testes in vitro estão mostrados nas Figura 4 e 5. Nestas figuras, espectros de FTIR foram obtidos para analisar o processo de transformação superficial que usualmente ocorre durante a introdução de materiais bioativos em ambiente corpóreo (ou simulador do ambiente corpóreo). A Figura 4 mostra os espectros de FTIR para todas as composições estudadas após vinte horas in vitro, enquanto que na Figura 5, espectros para as mesmas composições relativas à Figura 4, mas após 30 dias in vitro, são exibidos. Observa-se bioatividade apenas nos compósitos de 50\% em massa de partículas, nos períodos de vinte horas e 30 dias, que

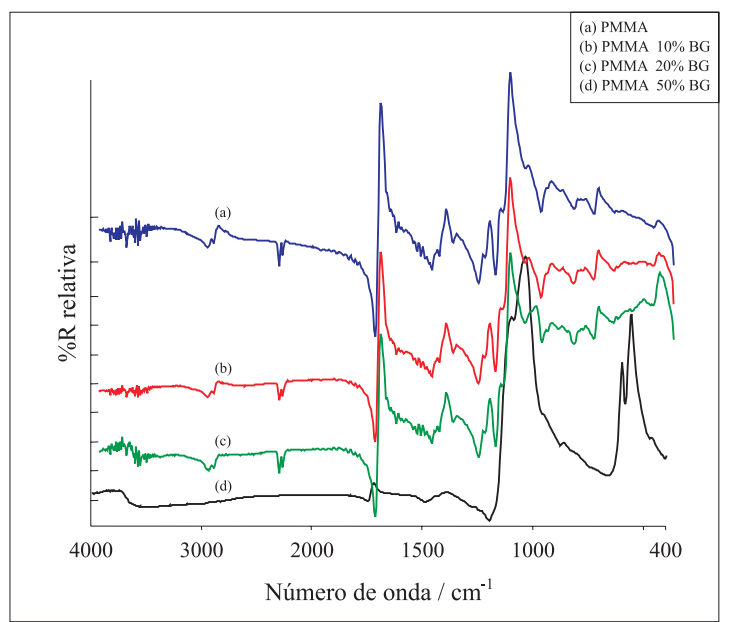

Figura 5. Espectros de FTIR para compósitos após 30 dias in vitro 


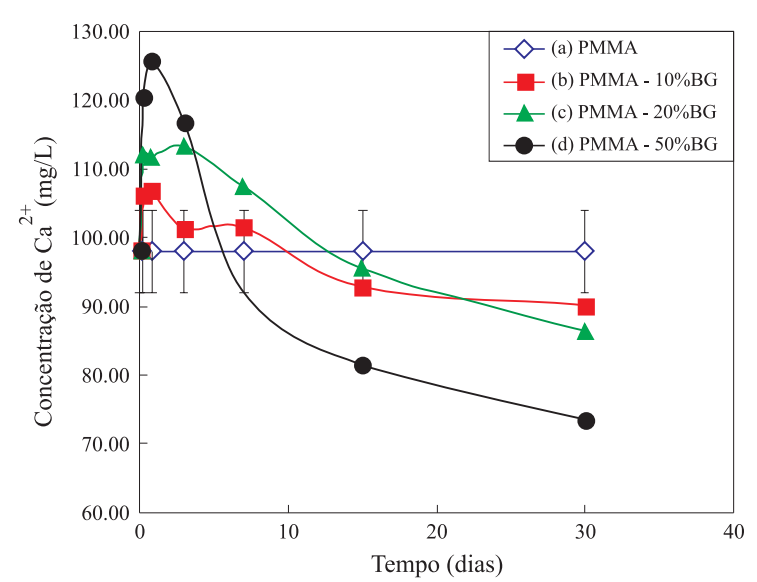

Figura 6. Evolução da concentração de Cálcio na solução SBF durante o ensaio in vitro para todas as composições estudadas

pode ser claramente verificada pelas bandas de 1040, 600 e $560 \mathrm{~cm}^{-1}$ referentes à formação da camada de HCA (ligações P-O). Para os compósitos com outras composições, os espectros de FTIR obtidos se mostram muito semelhantes aos espectros dos compósitos antes do teste in vitro, o que sugere a ausência de um filme espesso e uniforme de hidroxiapatita carbonatada por toda a superfície do compósito.

As reações superficiais que ocorrem durante o teste in vitro podem ser acompanhadas através das alterações da concentração do íon $\mathrm{Ca}^{2+}$ presente na solução SBF empregada durante o ensaio. Na Figura 6 observa-se a variação da concentração do $\mathrm{Ca}^{2+}$ na solução SBF, em função do tempo de ensaio. Este resultado, quando associado aos espectros de FTIR, permite analisar a bioatividade in vitro e identificar os estágios de reações que culminam com a formação da camada de HCA, de acordo com a Tabela 1.

\section{Discussão}

Os resultados revelados nas Figuras 1 a 3 permitem indicar a efetividade do método usado no processamento dos compósitos em se obter materiais com composições previamente projetadas (Figura 1, TGA), elevado grau de homogeneidade de distribuição das partículas na matriz polimérica (Figura 2, MEV, sendo que este resultado pode ser estendido para as demais composições uma vez que a metodologia utilizada foi a mesma) e indicação de interações interfaciais (interface polímeropartícula) medianas (Figura $2 \mathrm{MEV}$ ).

Além disso, as informações fornecidas nas figuras 4, 5 e 6 são importantes para uma análise mais completa da bioatividade desses materiais. Estudos ante- riores $^{[5]}$ identificaram a existência de 5 estágios de reações que ocorrem nos materiais bioativos (como nos vidros bioativos puros), que resultam na ligação espontânea com os tecidos vivos, designada de fixação bioativa. Estas reações produzem uma camada superficial de hidroxiapatita carbonatada no material implantado que é reconhecida por entidades biológicas como parte do sistema corpóreo. Este bioreconhecimento promove interação e finalmente adesão entre essas entidades e a superfície do material (caracterizando a bioatividade). Nas figuras 4-d e 5-d, são mostrados os picos referentes a formação de HCA para o compósito com $50 \%$ de partículas, após respectivamente 20 horas e 30 dias. Além disso, nesses espectros as bandas relativas ao polímero puro não são identificadas, o que indica a presença de um filme de HCA espesso e uniformemente distribuído por toda a superfície do material. A não formação desta camada uniforme e espessa de HCA nas amostras com composições mais pobres em partículas até 30 dias, revela que serão possivelmente necessários tempos mais longos de ensaio. Assim a cinética de deposição de HCA depende da composição do compósito. Além disso, este resultado mostra a possibilidade de se manipular a bioreatividade dos compósitos a partir de variáveis de projeto do compósito, como a fração de partículas.

Através da análise química quantitativa do íon cálcio presente na solução SBF, em função do tempo de ensaio in vitro, é possível estabelecer uma relação com os estágios de formação da camada de HCA. A concentração de $\mathrm{Ca}^{+2}$ foi medida em função do tempo de ensaio para o PMMA puro e para os compósitos contendo 10\%, 20\% e 50\% em massa de partículas. O PMMA puro, por não apresentar qualquer nível de bioatividade devido a ausência desse íon em sua composição, não proporcionou nenhuma variação na concentração de cálcio da solução. As variações apresentadas pela curva do compósito contendo $10 \%$ em massa de partículas estão dentro da faixa de erro de medição constatada.

$\mathrm{Na}$ curva referente às amostras de $20 \%$ em massa de partículas de vidro bioativo, observou-se uma elevação da concentração de cálcio até 3 dias, sendo este pico resultado da migração dos íons $\mathrm{Ca}^{+2}$ do compósito para a solução SBF, relativos aos estágios 1 e 2 (Tabela 1). A redução suave na concentração de cálcio na solução após este tempo pode significar a deposição de uma camada de pequena espessura e dispersa de HCA na superfície do material, a qual não foi notada por FTIR.

A solução referente ao teste in vitro, realizado no 
compósito com composição com 50\% em massa de partículas, apresentou uma elevação pronunciada da concentração de cálcio até 20 horas, sendo isto resultado do processo de lixiviação do cálcio presente na estrutura do compósito para a SBF (estágios 1 e 2 - Tabela 1). Nesse ponto, a solução atinge a saturação e a concentra-

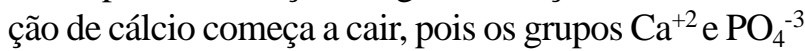
da solução migram para a superfície do biomaterial, formando uma camada amorfa de CaP (estágio 4). Finalmente a incorporação dos ânions $\mathrm{OH}^{-}$e $\mathrm{CO}_{3}^{-2}$ conduz à cristalização da camada de HCA (estágio 5).

A relação entre fração dos componentes e a cinética de indução para precipitação da camada de hidroxiapatita carbonatada está associada ao tempo necessário para que ocorra uma supersaturação da solução com os íons liberados pelas partículas do sistema. Assim, o comportamento in vitro de compósitos com pequena fração volumétrica de fase bioativa pode ser assim proposto: partículas de vidro dispostas na superfície dos compósitos contribuem de maneira quase imediata com a liberação de íons $\left(\mathrm{Ca}^{2+}, \mathrm{Na}^{+} \mathrm{e}\right.$ $\left.\mathrm{PO}_{4}{ }^{-3}\right)$ móveis presentes em sua estrutura para a solução SBF; o aumento de concentração resultante dessa liberação inicial não é suficiente para induzir a precipitação de HCA; com o passar do tempo, íons oriundos de partículas mais distantes das superfícies são liberados para a solução através de processos de migração pelas interfaces dos compósitos; finalmente a concentração da solução SBF atinge níveis de supersaturação que podem, então, levar a precipitação da camada de HCA.

A presença de superfícies múltiplas em compósitos pode também explicar o fato de que compósitos com 50\% em massa de material bioativo foram capazes de reproduzir o comportamento de materiais bioativos puros, quanto à cinética de precipitação da camada de $\mathrm{HCA}^{[6]}$. Ou seja, tanto os compósitos com $50 \%$ em massa de partículas de vidro bioativo como vidros bioativos puros, induzem a precipitação da camada de HCA após as primeiras 20 horas em contato com uma solução simuladora do ambiente corpóreo. Visto que tais compósitos apresentam inerentes maiores facilidades para processamento (usinabilidade, por exemplo) e potenciais maiores resistência mecânica e tenacidade à fratura que as próprias biocerâmicas puras, percebe-se que os materiais desenvolvidos neste trabalho apresentam-se extremamente interessantes do ponto de vista de substituir com ganhos as biocerâmicas em aplicações biomédicas.

\section{Conclusões}

Este trabalho demonstrou a possibilidade de se produzir compósitos PMMA-vidro bioativo através da polimerização em massa do metacrilato de metila na presença de partículas de vidro. Os compósitos produzidos apresentaram-se com boa homogeneidade de distribuição de partículas na matriz e com resistências mecânicas interfacial (partícula-matriz) de magnitude intermediária a elevada, como sugerido pelas análises DSC e MEV. Os compósitos obtidos com 50\% em massa de partículas apresentaram bioatividade após vinte horas quando submetidos à ensaios in vitro em solução simuladora de ambiente corpóreo a $37^{\circ} \mathrm{C}$. Tal bioatividade foi atestada a partir da detecção da presença de uma camada de hidroxiapatita carbonatada na superfície do compósito. Assim sendo, compósitos contendo vidro bioativo apresentam bioatividade in vitro característica dos materiais bioativos e controlável a partir da composição do sistema. Tais compósitos surgem, assim, como potenciais candidatos a substituir, com ganhos, biocerâmicas em aplicações biomédicas.

\section{Agradecimentos}

Os autores agradecem a FAPEMIG pelo apoio financeiro a este projeto.

\section{Referências Bibliográficas}

1. Hench, L. L. - The challenge of orthopaedic materials. Current Orthopaedics, n. 14, p. 5-15, (2000).

2. Hench, L. L., West, J. K. - Bioactive Materials, Life Chem. Report., 13, p. 187 (1996).

3. Hench, L.L. - Bioceramics: from concept to clinic, J.Am. Ceram. Soc., 74, n.7, p.1487-1510, (1991).

4. Oréfice, R. L., Latorre, G. P.,West, J. K., Hench, L. L. Processing and Characterization of Bioactive Polysulfone-Bioglass ${ }^{\circledR}$ Composites, Bioceramics 8 , p.400-414, (1995).

5. Latorre, G. P., Hench, L. L. Analysis of bioactive glass interfacial reactions using Fourier Transform Infrared Reflection Spectroscopy. In: Characterization methods for the solid solution interface in ceramic systems, Ed. ACS, (1993).

6. Oréfice, R. L.; Hench, L. L.; Brennan, A. B. - In vitro bioactivity of polymer matrices reinforced with a bioactive phase. J. Brazilian Chemical Society, v. 11, n. 1, p. 78-87, (2000).

Recebido: 23/03/01

Aprovado: 27/09/01 